\title{
Differential gene expression analysis in treatment of Parkinson's disease using the moduli space of triangles
}

\author{
Amir Assadi*1, Mary Kloc², Gregory Michelotti³, Colin Davidson ${ }^{4}$, \\ Everett $\mathrm{H}$ Ellinwood ${ }^{4}$ and Tong Lee ${ }^{4}$
}

\author{
Address: ${ }^{1}$ Department of Mathematics, University of Wisconsin-Madison, Madison, WI 53706, USA, ${ }^{2}$ Biophysics Program, University of \\ Wisconsin-Madison, Madison, WI 53706, USA, ${ }^{3}$ Department of Anesthesiology, Duke University \& Medical Center, Durham, NC 27710, USA and \\ ${ }^{4}$ Department of Psychiatry, Duke University \& Medical Center, Durham, NC 27710, USA \\ Email: Amir Assadi* - ahassadi@facstaff.wisc.edu; Mary Kloc - kloc@wisc.edu \\ * Corresponding author
}

from Sixteenth Annual Computational Neuroscience Meeting: CNS*2007

Toronto, Canada. 7-12 July 2007

Published: 6 July 2007

BMC Neuroscience 2007, 8(Suppl 2):PI33 doi:I0.I I86/I47I-2202-8-S2-PI33

C 2007 Assadi et al; licensee BioMed Central Ltd.

The long-term utility of levodopa (l-dopa) treatment against PD is known to be limited by its subsequent induction of dyskinesia (1-dopa-induced dyskinesia or LID). Up to now, few treatment strategies have been identified to reverse LID and restore l-dopa efficacy in dyskinetic patients. Among various mechanisms, l-dopa sensitization ("priming") may play an important role in the development and maintenance of LID. Disregulation of dopamine (DA) synthesis, release and clearance of extracellular DA (due to DA neuronal death and consequent "ectopic" synthesis and release by 5 -HT terminals) is thought to lead to exaggerated fluctuations in the synaptic DA concentrations and consequent neurobiological alterations during chronic intermittent l-dopa treatment. These fluctuations, in turn, induce long-term, synaptic alterations in the striatum and other brain areas comprising the basal ganglia. Previous studies have shown that long-term sensitization to cocaine can be reversed by injecting a dopamine receptor agonist, followed by a 5 HT2 or 5-HT3 antagonist approximately 3.5 hours later $[1,2]$. To the extent that cocaine addiction may share similar neurobiological mechanisms with LID, it is reasonable to examine a regimen of the DA agonist pergolide followed by the 5-HT2 antagonist ketanserin at the peak of acute withdrawal over a treatment period and reverse sensitization to l-dopa. Based on our previous finding that this specific drug combination regimen can reverse previ- ously-established behavioral and molecular markers of cocaine or methamphetamine sensitization in rats [3], we determined the striatal mRNA expression profiles associated with l-dopa-induced dyskinesia in rats and its reversal by the pergolide-ketanserin regimen. 6-Hydroxydopamine (6-OHDA)-lesioned rats were treated with ldopa twice a day for 21 days (days $1-21$ ) to induce abnormal involuntary movements (AIM), a model of LID. Subsequently, they were treated subcutaneously once a day for 2 weeks with one of the following. Group A received pergolide followed by ketanserin; Group B received pergolide followed by saline; Group $\mathrm{C}$, the control group, received saline on both occasions. The expression levels of mRNA were measured for 27,342 genes. The normalized values provide triplets of positive numbers $\mathrm{D}$ $=\{(A(n), B(n), C(n)): n=1,2, \ldots 27342\}$. This paper reports progress in application of new mathematical methods for exploring this genome-scale gene expression data. The main geometric idea is to represent the data as a collection of points in a space that parameterizes congruence classes of triangles in the plane. The distinguishing advantage of this approach is in extracting significant (biological) features and patterns of triangle shapes that are not typically discernible by commonly used statistical analyses. This method is applied to the data set $\mathbf{D}$, where a relatively small group of genes are identified and tabulated. 


\section{References}

I. Davidson C, Lee TH, Xiong X, Ellinwood EH: Ondansetron given in the acute withdrawal from a repeated cocaise sensitization dosing regimen reverses the expression of sensitization and inhibits self-administration. Neuropsychopharmacology 2002, 27:542-553.

2. Davidson C, Lazarus C, Xiong X, Lee TH, Ellinwood EH: 5-HT2 receptor antagonists given in the acute withdrawal from daily cocaine injections can reverse established sensitization. EurJ Pharmacol 2002, 453:255-263.

3. Zhang X, Lee TH, Davidson C, Lazarus C, Wetsel WC, Ellinwood EH: Reversal of cocaine-induced behavioural sensitization and associated phosphorylation of the NR2B and GluRI subunits of the NMDA and AMPA receptors. Neuropsychopharmacology 2007, 32:377-387.

Publish with Bio Med Central and every scientist can read your work free of charge

"BioMed Central will be the most significant development for disseminating the results of biomedical research in our lifetime. "

Sir Paul Nurse, Cancer Research UK

Your research papers will be:

- available free of charge to the entire biomedical community

- peer reviewed and published immediately upon acceptance

- cited in PubMed and archived on PubMed Central

- yours - you keep the copyright

Submit your manuscript here:

http://www.biomedcentral.com/info/publishing_adv.asp 